\title{
Effects of Physician Supply on Early Detection of Breast Cancer
}

\author{
Jeanne M. Ferrante, MD, Eduardo C. Gonzalez, MD, Naazneen Pal, MPH, and \\ Richard G. Roetzheim, MD, MSPH
}

Background: There are few studies examining the effects of physician supply on health-related outcomes. We hypothesized that increasing physician supply and, in particular, increasing primary care supply would be related to earlier detection of breast cancer.

Metbods: Information on incident cases of breast cancer occurring in Florida in $1994(\mathrm{n}=11,740)$ was collected from the state cancer registry. Measures of physician supply were obtained from the 1994 AMA Physician Masterfile. The effects of physician supply on the odds of late-stage diagnosis were examined using multiple logistic regression.

Results: There was no relation between overall physician supply and stage of breast cancer of diagnosis. Each 10 th percentile increase in primary care physician supply, however, resulted in a $4 \%$ increase in the odds of early-stage diagnosis (adjusted odds ratio $=1.04,95 \%$ confidence interval $=$ 1.01-1.06).

Conclusions: The supply of primary care physicians was significantly associated with earlier stage of breast cancer at diagnosis. This study suggests that an appropriate balance of primary care and specialty physician supply might be an important predictor of health outcomes. (J Am Board Fam Pract 2000;13:408-14.)

Breast cancer is the most common cancer in women and the second leading cause of cancer mortality in women in the United States. In 1999 there were 176,300 estimated new cases of breast cancer and 43,700 deaths from breast cancer in the United States. ${ }^{1}$ The 5 -year survival rate is $97 \%$ for patients with local stage, but decreases to $78 \%$ for regional spread, and $22 \%$ for distant disease. ${ }^{2}$ Later stage at diagnosis for breast cancer has been previously shown to be associated with certain patient characteristics, such as postmenopausal age, ${ }^{3}$ AfricanAmerican race, ${ }^{3-5}$ low education, ${ }^{3}$ being unmarried, ${ }^{4,6}$ having low income ${ }^{4}$ having no insurance, ${ }^{4,5}$ or having Medicare fee-for-service insurance versus insurance through a health maintenance organization (HMO). ${ }^{7}$

Little is known, however, about physician factors and their influence on stage of diagnosis for

Submitted, revised, 13 March 2000.

From the Department of Family Medicine (JMF, ECG, NP, RGR), University of South Florida, and the H. Lee Moffitt Cancer Center \& Research Institute (JMF, RGR), Tampa. Address reprint requests to Richard G. Roetzheim, MD, MSPH, Department of Family Medicine, University of South Florida, 12901 Bruce B. Downs Blvd, MDC 13, Tampa, FL 33612.

Dr. Roetzheim was supported through Generalist Physician Faculty Scholars Awards from the Robert Wood Johnson Foundation. breast cancer. Although there has been much discussion in the past several years about the supply of physicians in the United States and the balance of primary care to specialist physicians, ${ }^{8-18}$ there has been a shortage of studies examining the effects of physician supply on health-related outcomes. One study showed that patients residing in areas having fewer than 1 physician per 4,000 population had poorer survival rates from breast cancer. ${ }^{19}$ Some studies have found no difference in outcomes in such diseases as hypertension, diabetes mellitus, or alcoholism between primary care and specialty care, ${ }^{20-23}$ whereas others have suggested better health outcomes with specialty care for patients with acute myocardial infarction. ${ }^{24-26}$ Several investigators have argued that the balance between primary and specialty physician supply is irrelevant, and that the population level supply of primary care physicians is the only measure important for policy. ${ }^{15,17}$ Our previous study on early detection of colon cancer, however, did not support this premise and suggested that the balance between primary care and specialty physician supplies might well affect important health outcomes. ${ }^{27}$

We examined the effects of physician supply on stage of breast cancer at diagnosis for patients in Florida in 1994. Since breast cancer is amenable to 
screening through clinical breast examinations and mammography, physicians can have an impact on stage at diagnosis by performing clinical breast examinations and recommending screening mammograms to their patients. A physician's recommendation for screening and access to health care have been shown to be important predictors of breast cancer screening. ${ }^{28-30} \mathrm{We}$ therefore hypothesized that increasing physician supply would be associated with earlier stage of breast cancer at diagnosis. In addition, because most mammograms are ordered by primary care physicians rather than specialists, ${ }^{31}$ we hypothesized that a greater supply of primary care physicians would be associated with earlier stage at diagnosis for breast cancer.

This study was approved by the University of South Florida Institutional Review Board.

\section{Methods}

\section{Sources of Data}

Incident cases of breast cancer $(n=11,740)$ occurring in 1994 (the most current year for which all relevant data were available) were retrieved from the Florida Cancer Data System (FCDS), Florida's population-based statewide cancer registry. Breast cancers occurring in men were excluded. The FCDS has well-established methods to ensure complete case finding (including cooperative arrangements with other state tumor registries) and standardized procedures for quality control.

To include information that is not always available from the FCDS (insurance payer, comorbidity, socioeconomic status), cases were linked with state discharge abstracts. The State of Florida Agency for Health Care Administration (AHCA) maintains discharge abstracts for admissions to all nonfederal acute care hospitals, ambulatory surgical centers, free-standing radiation therapy centers, and diagnostic imaging centers. FCDS cases were linked with discharge abstracts through a probabilistic match based on social security number, sex, raceethnicity, and date of birth. Cases that successfully matched on all variables were considered valid matches (83.6\%). Matches were also considered valid if the sole discrepancy was a social security number or date of birth that differed by only one digit (suggesting data entry errors). Using this method 9,936 (85.5\%) of eligible cases were successfully matched, a rate similar to that achieved in another comparable study. ${ }^{32}$ Using 1990 US census data, each individual was assigned the median income-education level of either the census tract ( $92 \%$ of cases) or ZIP Code ( $8 \%$ of cases) of their residence. The use of census-derived measures of socioeconomic status have been validated in previous studies. ${ }^{33-36}$

The main outcome, stage at diagnosis, was defined as the summary stage at the time of diagnosis using the SEER Site-Specific Summary Staging Guide. ${ }^{37}$ For these analyses, stage at diagnosis was classified as either early stage (in situ, local) or late stage (regional, distant). Stage was available for $11,218(95.6 \%)$ cases.

Data on physician supply was obtained from the 1994 American Medical Association (AMA) Physician Masterfile, which includes allopathic and osteopathic physicians regardless of AMA membership. ${ }^{38}$ Population estimates were obtained from the 1990 US census. Physician supply variables were created for total physician supply, primary care physician supply, and non-primary-care physician supply. Primary specialty is self-designated by physicians as the specialty in which they spend most of their clinical time. Physicians were classified as primary care if their primary specialty was either family practice, general practice, obstetricsgynecology, or general internal medicine, regardless of their secondary specialty designation. ${ }^{39,40}$ Primary care practice content has been verified for physicians meeting this definition. ${ }^{41}$ In contrast, physicians who indicate a primary care field only as their secondary specialty have been found to have markedly less primary care practice content. ${ }^{41}$ Physicians who indicated they were engaged in fulltime direct patient care were counted as one fulltime equivalent (FTE); those who indicated in the Masterfile that they were either semi-retired, in residency training, or also engaged in teaching or research were counted as 0.5 FTE. Physicians who indicated they were no longer involved in direct patient care were excluded. Previous studies have validated data contained in the 1994 AMA Physician Masterfile. ${ }^{38,42,43}$

To avoid measuring the impact of referral patterns, we assessed physician supply according to the patient's residence, not the location where their cancer was diagnosed. Physician supply was measured at the county level. There are 67 counties in Florida, which range in population from 5,569 to $1,937,094$. The median population for the 67 counties is 78,024 . 
Two physician supply variables were calculated for all cases: the number of physicians per capita and the number of primary care physicians as a percentage of all physicians. We used the proportion of physicians engaged in primary care as the measure of primary care physician supply in multivariate models. ${ }^{44}$

Other variables that were controlled in multivariate analyses included age, marital status (never married, married, divorced, separated, widowed), race-ethnicity (white [non-Hispanic], AfricanAmerican [non-Hispanic], Hispanic, or other), insurance payer (Medicare, Medicare HMO, Medicaid, commercial indemnity, commercial preferred provider organization, commercial HMO, uninsured, and other (includes CHAMPUS [Civilian Health and Medical Program of the Uniformed Services], Veterans Administration, workers' compensation, other state or local government programs), and comorbidity. Comorbidity was determined using methods described by Deyo et al and Charlson et al. ${ }^{45,46}$ We used the International Classification of Disease, 9th Revision, Clinical Modification (ICD-9-CM) mapping of comorbid conditions as described by Deyo et al. ${ }^{45}$ Cancer-related conditions were excluded. We used the original weights described by Charlson et al in calculating a morbidity index (theoretical range $0-23$ ). We defined three categories of comorbidity $(0,1,2+)$ based on the patient's index score.

\section{Multivariate Analysis}

We examined the relation between primary care supply and the odds of early-stage diagnosis using multiple logistic regression. Potential confounding variables were modeled in a similar fashion in all logistic models: age (as a continuous variable), level of education (three indicator variables), level of income (four indicator variables), insurance payer (seven indicator variables), race-ethnicity (three indicator variables), comorbidity (single ordinal variable), and marital status (four indicator variables).

To allow for nonlinear relations between primary care physician supply and the odds of earlystage diagnosis, indicator variables were created by percentiles of primary care physician supply. ${ }^{47}$ Cases in the lowest 10th percentile of primary care supply were designated as the referent group, and nine indicator variables were created corresponding to each 10th percentile increase in the primary care physician supply. Relations were then exam- ined by graphing the nine corresponding odds ratios. ${ }^{48-50}$ Linear relations between primary care physician supply and the odds of early-stage diagnosis were subsequently tested in logistic models using the chi-square likelihood ratio test. ${ }^{47}$ Odds ratios for primary care physician supply were also adjusted for total physician supply. We anticipated that the proportion of physicians who were engaged in primary care would be associated with overall physician supply because of the need for specialists to concentrate in sufficiently large population centers. Areas with a high proportion of specialists probably have a high overall physician supply. Any association found between the proportion of physicians in primary care and the early detection of breast cancer, therefore, might be confounded by overall physician supply. For that reason, we included a measure of overall physician supply to multivariate models.

That all patients residing in the same county are assigned the same measure of physician supply might lead to correlation of error terms. Clustering by county could lead to underestimation of standard errors in logistic models. ${ }^{51}$ To examine this possibility we re-estimated parameters and their errors using the method of generalized estimating equations, which controls for clustered or correlated data. ${ }^{52,53}$

Because physician supply was likely to be correlated with community characteristics, we also stratified analyses by urban-nonurban residence, and by high (above the median) versus low (below the median) socioeconomic area of residence.

\section{Results}

Reflecting the demographics of the state of Florida, the mean age for breast cancer patients was 71.5 years (SD 11.6 years). The median household income was $\$ 28,929$ (SD \$10,593). Table 1 shows the characteristics of the study population. White, non-Hispanic women constituted most of the patients $(83.8 \%)$. The most common insurance payer was Medicare, and most breast cancers $(71 \%)$ were diagnosed at an early stage (in situ or local stage).

Physician supply for cases of breast cancer is reported in Table 2. Overall, specialist physicians outnumbered primary care physicians two to one. Most breast cancer patients resided in counties in which primary care physicians accounted for less than one third of the physician workforce. 
Table 1. Characteristics of Women With a Diagnosis of Breast Cancer, in Florida, $1994(n=11,740)$.

\begin{tabular}{|c|c|c|}
\hline Characteristics ' & Number ${ }^{\star}$ & Percent \\
\hline \multicolumn{3}{|l|}{ Race or ethnicity } \\
\hline White, non-Hispanic & 9,735 & 83.8 \\
\hline African-American, non-Hispanic & 805 & 6.9 \\
\hline Hispanic & 878 & 7.6 \\
\hline Other & 200 & 1.7 \\
\hline \multicolumn{3}{|l|}{ Education $^{\dagger}$} \\
\hline High school or less & 4,992 & 43.2 \\
\hline More than high school & 6,557 & 56.7 \\
\hline \multicolumn{3}{|l|}{ Marital status } \\
\hline Never & 1,022 & 9.0 \\
\hline Current & 6,507 & 57.4 \\
\hline Divorced, separated & 1,042 & 9.2 \\
\hline Widowed & 2,759 & 24.4 \\
\hline \multicolumn{3}{|l|}{ Payer } \\
\hline Medicare & 4,822 & 46.2 \\
\hline Medicare HMO & 439 & 4.2 \\
\hline Medicaid & 258 & 2.5 \\
\hline Commercial insurance & 1,725 & 16.5 \\
\hline Commercial HMO & 1,135 & 10.9 \\
\hline Commercial PPO & 1,192 & 11.4 \\
\hline Uninsured & 491 & 4.7 \\
\hline Other & 383 & 3.7 \\
\hline \multicolumn{3}{|l|}{ Stage of breast cancer } \\
\hline In situ & 1,396 & 12.6 \\
\hline Local & 6,441 & 58.0 \\
\hline Regional & 2,666 & 24.0 \\
\hline Distant & 593 & 5.3 \\
\hline
\end{tabular}

*Numbers for individual categories might not sum to total sample size because of missing data.

${ }^{\dagger}$ By census tract or ZIP Code residence.

HMO-health maintenance organization, PPO-preferred provider organization.

We found no relation between overall physician supply and stage of breast cancer at diagnosis (adjusted odds ratio $[\mathrm{OR}]=1.000,95 \%$ confidence interval [CI] 0.999-1.0005, $P=.595$ ). There was, however, a significant relation between primary care physician supply and early-stage diagnosis of breast cancer. The effects of primary care physician supply on the odds of early-stage diagnosis, controlling for patient characteristics and total physician supply, are presented in Figure 1. The odds of early-stage diagnosis increased as the proportion of physicians who were in primary care increased. This relation fit a linear model $(O R=1.04,95 \%$ CI 1.01-1.06; $\chi^{2}$ for linear trend $=7.3, P=.007$ ). The resultant linear model predicts that for each 10th percentile increase in primary care physician supply there is a $4 \%$ increase in the odds of earlystage diagnosis.

We re-estimated model parameters and errors using the method of generalized estimating equations to control for any effects of clustering within the data. Results were similar (adjusted $\mathrm{OR}=1.03$, 95\% CI 1.01-1.06, $P=.003$ ).

Logistic regressions were repeated stratified by urban-nonurban place of residence. There was no association between primary care physician supply for the 5,160 patients residing in urban settings (adjusted OR $=1.01,95 \%$ CI 0.97-1.06, $P=.55$ ). Among the 4,786 patients residing in nonurban settings, however, increasing primary care physician supply was associated with greater odds of early-stage diagnosis (adjusted $\mathrm{OR}=1.05,95 \% \mathrm{CI}$ $1.01-1.08, P=.007)$.

Results were similar when in situ cancers were excluded (adjusted OR $=1.04,95 \%$ CI 1.01-1.07, $P=.006, \mathrm{n}=8,993)$. Results were also similar when cases were restricted to ages for which mammography has a proven benefit (50 to 75 years) (adjusted OR $=1.04,95 \%$ CI 1.001-1.07, $P=.04$, $\mathrm{n}=5,985)$. Increasing supplies of primary care physicians were also associated with earlier detection of breast cancer among patients having feefor-service health insurance (adjusted $\mathrm{OR}=1.03$, $95 \%$ CI 1.004-1.06, $P=.02, \mathrm{n}=8,414)$. The effects of increasing primary care supply on the early detection of breast cancer were greater in magnitude among patients having HMO insurance, but this association did not reach statistical significance because of the much smaller sample size (adjusted OR $=1.06,95 \%$ CI $0.98-1.15, P=.15$, $\mathrm{n}=1,532)$. The effects of primary care physician supply on the early detection of breast cancer were similar among patients living in areas below the median of socioeconomic status (adjusted OR = $1.035,95 \%$ CI $0.999-1.11, P=.05$ ), compared with those living in areas above the median of socioeconomic status (adjusted OR $=1.033,95 \%$ CI $0.993-1.08, P=.10$ ).

\section{Conclusions}

Although there was no relation between overall physician supply and stage at diagnosis for patients with breast cancer, the supply of primary care physicians was significantly associated with stage at diagnosis. As the supply of primary care physicians increased, the odds of early-stage diagnosis increased. In stratified analysis, the effects of primary 
Table 2. Physician Supply for Patients with Breast Cancer, Florida, 1994* $(\mathrm{N}=10,976)$.

\begin{tabular}{lccc}
\hline Physician Supply ${ }^{\dagger}$ & Mean (SD) & Median & Range \\
\hline Total physicians & $209.8(67.2)$ & 220.0 & $15.5-561.4$ \\
Primary care physicians & $64.7(15.4)$ & 66.9 & $9.1-125.0$ \\
Family practice & $18.1(5.7)$ & 16.6 & $0.0-41.3$ \\
General practice & $10.3(4.9)$ & 8.6 & $0.0-33.5$ \\
Internal medicine & $24.4(8.9)$ & 24.2 & $0.0-47.4$ \\
Obstetrics-gynecology & $11.9(4.1)$ & 11.2 & $0.0-25.1$ \\
Specialty physicians & $145.0(52.9)$ & 152.6 & $0.0-436.4$ \\
Proportion of physicians in primary care & $32.1 \%(6.6 \%)$ & $30.4 \%$ & $22.3 \%-100 \%$ \\
\hline
\end{tabular}

*Physicians per 100,000 population.

${ }^{\dagger}$ Physician supply measured at the county level.

care physician supply on stage of breast cancer at diagnosis were more pronounced for patients having fee-for-service insurance, for those living in nonurban areas, for patients with invasive cancers, and for those in the 50- to 75-year age-group for which mammograms have a proven benefit.

The odds ratio comparing patients in the highest percentile of primary care supply to patients in the lowest percentile is 1.37 , indicating that patients residing in areas with the highest primary care physician supply have $37 \%$ greater odds of early-stage diagnosis compared with patients residing in areas having the lowest primary care physician supply. This odds ratio is similar in magnitude to the odds ratio we have previously reported comparing commercial-indemnity-insured patients to those lacking health insurance (1.43). ${ }^{5}$

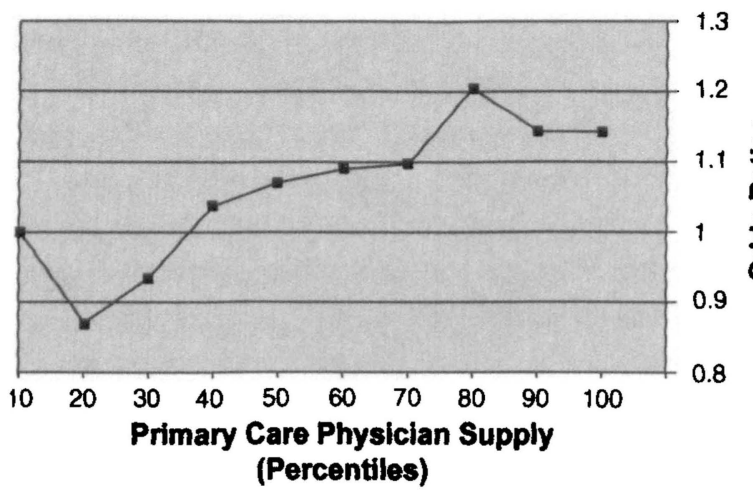

Primary care physician supply and the odds of earlystage breast cancer diagnosis. Test of linear trend $\left(X^{2}=7.30, P=.007\right)$. Odds ratios adjusted for patients' age, race-ethnicity, marital status, insurance payer, comorbidity, community measures of education and income, and total physician supply. Odds ratios are relative to patients in the lowest 10th percentile of primary care physician supply.
Mammography use has been shown previously to explain racial differences in stage at diagnosis of breast cancer. ${ }^{54}$ Likewise, mammography use could explain why the supply of primary care physicians might contribute to earlier detection of breast cancer. The National Ambulatory Medical Care Survey showed that in $1991,87 \%$ of all mammograms were recommended by primary care physicians rather than specialists. ${ }^{31}$ Primary care physicians tend to recommend preventive care services during visits for chronic illnesses more so than specialists. ${ }^{41,55,56}$

There are a number of potential limitations in this study. First, the relations found might be the result of confounding with some other factor. The multivariate models, however, controlled for patients' age, race-ethnicity, marital status, comorbidity, type of health insurance, and community measures of socioeconomic status. Second, socioeconomic status was not measured at the individual level. Previous studies, however, have validated the use of aggregate measures of socioeconomic status. ${ }^{33-36}$ In addition, whereas physician supply is an important variable relevant to health care policy, it can be considered only an aggregate measure of individual patient use of physician services. The patients that were studied might have had actual use of physician services that were not reflected by the measure of physician supply studied. It will be important to measure actual use of physician services at the individual patient level in future research to confirm these relations. Lastly, our study was restricted to incident cases of breast cancer in Florida, which might not be representative of other diseases or other parts of the country.

In conclusion, we found that an increasing supply of primary care physicians was associated with 
earlier stage of breast cancer at diagnosis. This study suggests that the composition of the physician workforce, mainly an appropriate balance of primary care and specialty physician supply, might be an important predictor of health outcomes. In the meantime, subspecialists, who may be the only physician a patient ever sees, should make an effort to ensure that their patients are being adequately screened for breast cancer, if not by themselves, then by other physicians.

\section{References}

1. Landis S, Murray T, Bolden S, Wingo PA. Cancer statistics, 1999. CA Cancer J Clin 1999;49:8-31.

2. Greenlee RT, Murray T, Bolden S, Wingo PA. Cancer statistics, 2000. CA Cancer J Clin 2000;50:7-33.

3. Mandelblatt J, Andrews H, Kerner J, Zauber A, Burnett $W$. Determinants of late stage diagnosis of breast and cervical cancer: the impact of age, race, social class, and hospital type. Am J Public Health 1991;81:646-9.

4. Lannin DR, Mathews HF, Mitchell J, Swanson MS, Swanson FH, Edwards MS. Influence of socioeconomic and cultural factors on racial differences in late-stage presentation of breast cancer. JAMA 1998; 279:1801-7.

5. Roetzheim RG, Pal N, Tennant C, et al. Effects of health insurance and race on early detection of cancer. J Natl Cancer Inst 1999;91:1409-15.

6. Goodwin JS, Hunt WC, Key CR, Samet JM. The effect of marital status on stage, treatment, and survival of cancer patients. JAMA 1987;258:3125-30.

7. Riley GF, Potosky AL, Lubitz JD, Brown ML. Stage of cancer at diagnosis for Medicare HMO and feefor-service enrollees. Am J Public Health 1994;84: 1598-604.

8. Barnett PG, Midtling JE. Public policy and the supply of primary care physicians. JAMA 1989;262: 2864-8.

9. Politzer RM, Harris DL, Gaston MH, Mullan F. Primary care physician supply and the medically underserved. A status report and recommendations. JAMA 1991;266:104-9.

10. Rosenblatt RA. Specialists or generalists. On whom should we base the American health care system? JAMA 1992;267:1665-6.

11. Kindig DA, Cultice JM, Mullan F. The elusive generalist physician. Can we reach a $50 \%$ goal? JAMA 1993;270:1069-73.

12. Rivo ML, Satcher D. Improving access to health care through physician workforce reform. Directions for the 21st century. JAMA 1993;270:1074-8.

13. Schroeder SA. Training an appropriate mix of physicians to meet the nation's needs. Acad Med 1993; 68:118-22.

14. Weiner JP. Forecasting the effects of health reform on US physician workforce requirement. Evidence from HMO staffing patterns. JAMA 1994;272:22230.

15. Cooper RA. Seeking a balanced physician workforce for the 21st century. JAMA 1994;272:680-7.

16. Rivo ML, Mays HL, Katzoff J, Kindig DA. Managed health care. Implications for the physician workforce and medical education. Council on Graduate Medical Education. JAMA 1995;274:712-5.

17. Whitcomb ME. A cross-national comparison of generalist physician workforce data. Evidence for US supply adequacy. JAMA 1995;274:692-5.

18. Goodman DC, Fisher ES, Bubolz TA, Mohr JE, Poage JF, Wennberg JE. Benchmarking the US physician workforce. An alternative to needs-based or demand-based planning. JAMA 1996;276:1811-7.

19. Wilkinson GS, Edgerton F, Wallace HJ Jr, Reese P, Patterson J, Priore R. Delay, stage of disease and survival from breast cancer. J Chronic Dis 1979;32: $365-73$.

20. Greenfield S, Rogers W, Mangotich M, Carney MF, Tarlov AR. Outcomes of patients with hypertension and non-insulin dependent diabetes mellitus treated by different systems and specialties. Results from the Medical Outcomes Study. JAMA 1995;274:143644.

21. Mahajan RJ, Barthel JS, Marshall JB. Appropriateness of referrals for open-access endoscopy. How do physicians in different medical specialties do? Arch Intern Med 1996;156:2065-9.

22. Drummond DC, Thom B, Brown C, Edwards G, Mullan MJ. Specialist versus general practitioner treatment of problem drinkers. Lancet 1990;336: 915-8.

23. Ayanian JZ, Guadagnoli E, McNeil BJ, Cleary PD. Treatment and outcomes of acute myocardial infarction among patients of cardiologists and generalist physicians. Arch Intern Med 1997;157:2570-6.

24. Jollis JG, DeLong ER, Peterson ED, et al. Outcome of acute myocardial infarction according to the specialty of the admitting physician. $\mathrm{N}$ Engl $\mathrm{J}$ Med 1996;335:1880-7.

25. Nash IS, Nash DB, Fuster V. Do cardiologists do it better? J Am Coll Cardiol 1997;29:475-8.

26. Ayanian JZ, Hauptman PJ, Guadagnoli E, Antman EM, Pashos CL, McNeil BJ. Knowledge and practices of generalist and specialist physicians regarding drug therapy for acute myocardial infarction. $\mathrm{N} \mathrm{Engl}$ J Med 1994;331:1136-42.

27. Roetzheim RG, Pal N, Gonzalez EC, et al. The effects of physician supply on the early detection of colorectal cancer. J Fam Pract 1999;48:850-8.

28. Fox SA, Siu AL, Stein JA. The importance of physician communication on breast cancer screening of older women. Arch Intern Med 1994;154:2058-68.

29. Breen N, Kessler L. Changes in the use of screening mammography: evidence from the 1987 and 1990 
National Health Interview Surveys. Am J Public Health 1994;84:62-7.

30. Screening mammography: a missed clinical opportunity? Results of the NCI Breast Cancer Screening Consortium and National Health Interview Survey studies. JAMA 1990;264:54-8.

31. Schappert SM. National ambulatory medical care survey 1991 summary. Vital Health Stat 1994;13: $1-110$.

32. Ayanian JZ, Kohler BA, Abe T, Epstein AM. The relation between health insurance coverage and clinical outcomes among women with breast cancer. N Engl J Med 1993;329:326-31.

33. Diez-Roux AV. Bringing context back into epidemiology: variables and fallacies in multilevel analysis. Am J Public Health 1998;88:216-22.

34. Krieger N. Overcoming the absence of socioeconomic data in medical records: validation and application of a census-based methodology. Am J Public Health 1992;82:703-10.

35. Krieger N, Fee E. Social class: the missing link in U.S. health data. Int J Health Serv 1994;24:25-44.

36. Hofer TP, Wolfe RA, Tedeschi PJ, McMahon LF, Griffith JR. Use of community versus individual socioeconomic data in predicting variation in hospital use. Health Serv Res 1998;33(2 Pt 1):243-59.

37. Shambaugh E, Weiss $M$. Summary staging guide: cancer surveillance epidemiology and end results reporting. Bethesda, Md: US Dept. of Health Human Services, Public Health Service, National Institutes of Health; 1977.

38. Kenward $\mathrm{K}$. The scope of the data available in the AMA's Physician Masterfile. Am J Public Health 1996;86:1481-2.

39. Kindig DA. Counting generalist physicians. JAMA 1994;271:1505-7.

40. Obstetrician-gynecologists. Specialists in reproductive health care and primary physicians for women. ACOG statement of policy. Washington, DC: American College of Obstetrics-Gynecology, 1986.

41. Shea JA, Kletke PR, Wozniak GD, Polsky D, Escarce JJ. Self-reported physician specialties and the primary care content of medical practice: a study of the AMA Physician Masterfile. American Medical Association. Med Care 1999;37:333-8.

42. Grumbach K, Becker SH, Osborn EH, Bindman AB. The challenge of defining and counting general phy- sicians: an analysis of the Physician Masterfile data. Am J Public Health 1995;85:1402-7.

43. Williams PT, Whitcomb M, Kessler J. Quality of the family physician component of the AMA Masterfile. J Am Board Fam Pract 1996;9:94-9.

44. Welch WP, Miller ME, Welch HG, Fisher ES, Wennberg JE. Geographic variation in expenditures for physicians' services in the United States. N Engl J Med 1993;328:621-7.

45. Deyo RA, Cherkin DC, Ciol MA. Adapting a clinical comorbidity index for use with ICD-9-CM administrative databases. J Clin Epidemiol 1992;45:613-9.

46. Charlson ME, Pompei P, Ales KL, MacKenzie CR. A new method of classifying prognostic comorbidity in longitudinal studies: development and validation. J Chronic Dis 1987;40:373-83.

47. Hosmer DW, Lemeshow S. Applied logistic regression. New York: John Wiley \& Sons; 1989.

48. Kleinbaum DG, Kupper LL, Morgenstern H. Epidemiologic research: Principles and quantitative methods. New York: John Wiley \& Sons, 1982.

49. Rothman KJ. Modern epidemiology. Philadelphia: Lippincott-William and Wilkins, 1986.

50. Greenland S. Modeling and variable selection in epidemiologic analysis. Am J Public Health 1989;79: 340-9.

51. Liang KY, Zeger SL. Regression analysis for correlated data. Annu Rev Public Health 1993;14:43-68.

52. Zeger SL, Liang KY. Longitudinal data analysis for discrete and continuous outcomes. Biometrics 1986; 42:121-30.

53. Preisser JS, Koch GG. Categorical data analysis in public health. Annu Rev Public Health 1997;18:5182.

54. McCarthy EP, Burns RB, Coughlin SS, et al. Mammography use helps to explain differences in breast cancer stage at diagnosis between older black and white women. Ann Intern Med 1998;128:729-36.

55. Stange KC, Flocke SA, Goodwin MA. Opportunistic preventive services delivery. Are time limitations and patient satisfaction barriers? J Fam Pract 1998;46: 419-24.

56. Rosenblatt RA, Hart LG, Baldwin LM, Chan L, Schneeweiss $R$. The generalist role of specialty physicians: is there a hidden system of primary care? JAMA 1998;279:1364-70. 